\title{
THEOPHYLLINE-ETHYLENEDIAMINE IN THE MEASUREMENT OF BLOOD CIRCULATION-TIME
}

\author{
BY \\ D. N. ROSS \\ From the Royal Bath Hospital, Harrowgate
}

Received February 23, 1950

In the past few years, the surgical treatment of congenital cardiac abnormalities has led to a fresh interest in the measurement of blood circulation-time as a diagnostic aid (Allanby, 1949). Old controversies on the relative value of different methods have also been revived, so the time may be opportune for the description of an accurate method suitable for routine use in a busy outpatient department. The many methods that have been devised are based on the introduction into the blood stream at one point, of a substance that is detectable at another point by one or more of its physical or pharmacological properties.

The property of producing an intense taste in the mouth is the feature of the popular armtongue tests of Winternitz and his colleagues (1931) using the bitter decholin, and of Fishberg and his colleagues (1933) using saccharin: these tests have an entirely subjective end-point, and were therefore excluded in favour of others having an objective termination. The most accurate of the objective methods is that of Blumgart and Yens (1927) who used a radioactive salt which could be detected at various points by a special instrument; a simple method was devised by Fishback (1941) who injected a solution of fluorescein and observed the palpebral conjunctiva, under ultraviolet light in a dark room, for the first appearance of a brilliant yellow colour. Such methods require too much apparatus for our purposes, so our attention was directed upon the "histamine flush test" introduced by Weiss et al. (1929) in which an injected histamine solution produces a dilatation of the minute vessels of the face, noticeable to the observer as a flush: in an English trial of this method, Bain (1934) found that the injection of histamine could produce serious and perhaps fatal reactions.

In an interesting group of tests with an objective end-point the injected substance is a respiratory stimulant and produces a sharp increase in the depth of breathing, readily noticeable by the observer. The first substance to be used in this way was sodium cyanide, which was introduced by Loevenhart and his colleagues (1922) in the course of animal experiments, and was tried in man by Robb and Weiss (1933). Similar methods were devised by Berliner (1940), using alphalobeline, and by Elek and Solarz (1942), using papaverine, but were found to be unreliable.

In an effort to prevent atalectasis occurring in surgical cases as an early post-operative complication, Sperling, Weisman and Papermaster (1942) gave intravenous injections of theophyllineethylenediamine, and found that these produced a sudden increase in the rate and depth of respiration. Koster and Sarnoff (1943) observed so marked an increase in respiration, in many cases amounting to a gasp, that they decided to use it to measure the circulation time from the arm to the respiratory centre. Their series of 72 cases consisted of patients of both sexes and of all ages from 12 to 82 years, after operations, and in only one instance was there difficulty in recognizing the end-point: they did not take duplicate readings and the test was not performed on patients with cardiovascular, metabolic, or blood diseases.

For our purposes, a method of circulation-time measurement was required that would be 
safe and efficient, simple, and speedy to perform, and would not demand expensive or elaborate equipment: our attention, therefore, was concentrated on those methods based on respiratory stimulation. Previous work on the alpha-lobeline and papaverine tests did not suggest that they were likely to be satisfactory, so we were left with a choice between the cyanide and theophyllineethylenediamine methods-neither of which had been given an extensive trial in this country. Since the cyanides are such notorious poisons, it seemed unwise to use one of them for intravenous injection in a routine test while there was a reasonable alternative. It was decided then, to select theophylline-ethylenediamine, which had the additional advantage of being available commercially in sterile solution in convenient ampoules.

As has been stated, Koster and Sarnoff tried their new method in a relatively small number of normal cases only; it was necessary, therefore, before adopting the test for routine use, to give it a thorough trial in a larger number of normal subjects and in others suffering from those disorders that are known to affect the blood circulation time.

\section{Clinical Trials of the Theophylline-Ethylenediamine Test}

In this investigation, theophylline-ethylenediamine solution was used in the form of the proprietary cardophylin, which is available in ampoules of $2.0 \mathrm{ml}$., containing $0.48 \mathrm{~g}$. of the drug: since the dose is $1.0 \mathrm{ml}$., an ampoule is often sufficient for two tests.

The syringe is charged, a tourniquet is applied. to the right upper arm of the recumbent patient and an antecubital vein is entered; the tourniquet is released and, after a delay of a few seconds for the readjustment of the venous blood-flow, the syringe plunger and stopwatch cap are pressed simultaneously. The watch is stopped whenever the end-point occurs.

In order to avoid discrepancies, a $10 \mathrm{ml}$. syringe was always used, with a gauge 1 needle, for these make it possible for the $1 \mathrm{ml}$. of solution to be injected very rapidly, and since the piston stroke is only about $0.5 \mathrm{~cm}$. the syringe is easy to control. After some practice, the investigator finds no difficulty in manipulating the syringe with his right hand and the stop-watch with his left, but an assistant may take the watch.

\section{The Circulation-Time in Normal Subjects}

In this part of the trial, the routine test was performed on 150 subjects who were normal in that they did not suffer from diseases of the heart, of the blood, or of metabolism: they were typical adult hospital patients, of all ages, from the wards and out-patient clinics. The results (summarized in Table I) ranged from 6.8 to 22.0 seconds, with a mean of 12.1 and a standard deviation of $2 \cdot 3$ seconds.

TABLE I

Results in Control Subjects

\begin{tabular}{c|c|c|c}
\hline $\begin{array}{c}\text { No. of } \\
\text { Cases }\end{array}$ & Test & $\begin{array}{c}\text { Circulation-time (seconds) } \\
\text { Range of Readings }\end{array}$ & \multicolumn{1}{c}{ Remarks } \\
\hline 150 & single & $6 \cdot 8-22 \cdot 0$ & $\begin{array}{l}\text { Mean value 12.1 seconds. } \\
\text { Standard deviation } 2 \cdot 3 .\end{array}$ \\
\hline 50 & $\begin{array}{l}\text { (a) first } \\
(b) \text { second } \\
(c) \text { difference }\end{array}$ & $\begin{array}{r}7 \cdot 8-19 \cdot 6 \\
6 \cdot 8-20 \cdot 8 \\
0-2 \cdot 6\end{array}$ & $\begin{array}{l}\text { Mean difference between } \\
\text { first and second read- } \\
\text { ings } 1 \cdot 1 \text { seconds. }\end{array}$ \\
\hline
\end{tabular}

In order to find if the circulation-time is reasonably constant in the same subject, duplicate measurements were made in a further group of 50 normal subjects. Although maximum accuracy could be obtained only by performing each test under strictly basal conditions, these are unobtainable in general practice, hence the tests were made under normal ward conditions, with an interval of several days between the two. The results, which appear in Table I, show that the differences 
between first and second measurements range from 0 to 2.6 seconds, with a mean difference of $1 \cdot 1$ seconds.

In the 250 tests on 200 normal subjects there was no evidence of any constant relation between blood circulation-time and the subject's age, weight, pulse rate, or blood pressure: these details are omitted from the tables for the sake of simplicity.

Although the end-point is usually a sharp, deep inspiration amounting to a gasp, this may be preceded by a swallowing movement, a sudden change in facial expression denoting anxiety, or a catch in the breath during expiration. There is a temptation to wait for the dramatic gasp, but since it does not occur in a small percentage of tests, the first observable change should be regarded as the definite end-point (see Table II). In no case was there any dangerous reaction, but most

TABLE II

END-POINTS OBSERVEd IN NORMAL SUbJects

\begin{tabular}{|c|c|c|c|}
\hline Type & Description & No. of Cases & Percentage \\
\hline \multirow[t]{2}{*}{$\begin{array}{l}1 \\
2 \\
3 \\
4\end{array}$} & \multirow[t]{2}{*}{ 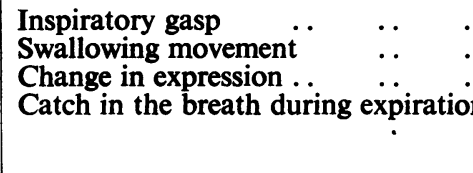 } & $\begin{array}{r}224 \\
15 \\
9 \\
2\end{array}$ & $\begin{array}{l}89 \cdot 6 \\
6 \\
3 \cdot 6 \\
0 \cdot 8\end{array}$ \\
\hline & & 250 & 100 \\
\hline
\end{tabular}

subjects spoke of a feeling of warmth over the face and of a light-headedness lasting for about half a minute: these side-effects were more prominent in excitable subjects, usually women, and in 8 cases-all confirmed psychoneurotics - they produced a violent emotional upset, with weeping, trembling, and tachycardia. Local reactions occurred only in the very few cases in which there was some leakage of the solution round the vein: this caused severe pain at the site of the leakage but was not followed by necrosis or thrombosis.

\section{Circulation-Time in Thyrotoxicosis}

These measurements were made under normal ward conditions, and the results of 33 tests in 21 cases are shown diagrammatically in Fig. 1 and in Table III.

Of 18 tests in these cases of hyperthyroidism, which had not been treated in any way, the circulation-time measurement ranged from 5.6 to 13.6 seconds, with a mean of $7 \cdot 1$ seconds. In the cases under treatment by thiouracil, or its derivatives, the measurements were appreciably higher, and successive tests showed that clinical improvement was paralleled by a rise in the circulationtime.

\section{Circulation-Time in Disorders of the BloOd}

The results of 41 tests in 29 cases of anæmia and two cases of polycythemia are shown in Fig. 1 and in Table III.

Comparison with blood count figures showed that the circulation-time was roughly parallel to the hæmoglobin level, and successive tests confirmed that an increase in that level was usually accompanied by an increase in the circulation-time.

\section{Circulation-Time in Cardiovascular Disease}

In this series, 108 tests were performed in 85 cases, which were grouped as follows;

(1) Hypertension uncomplicated by cardiac or renal failure- 8 cases.

(2) Rheumatic carditis -7 cases. 


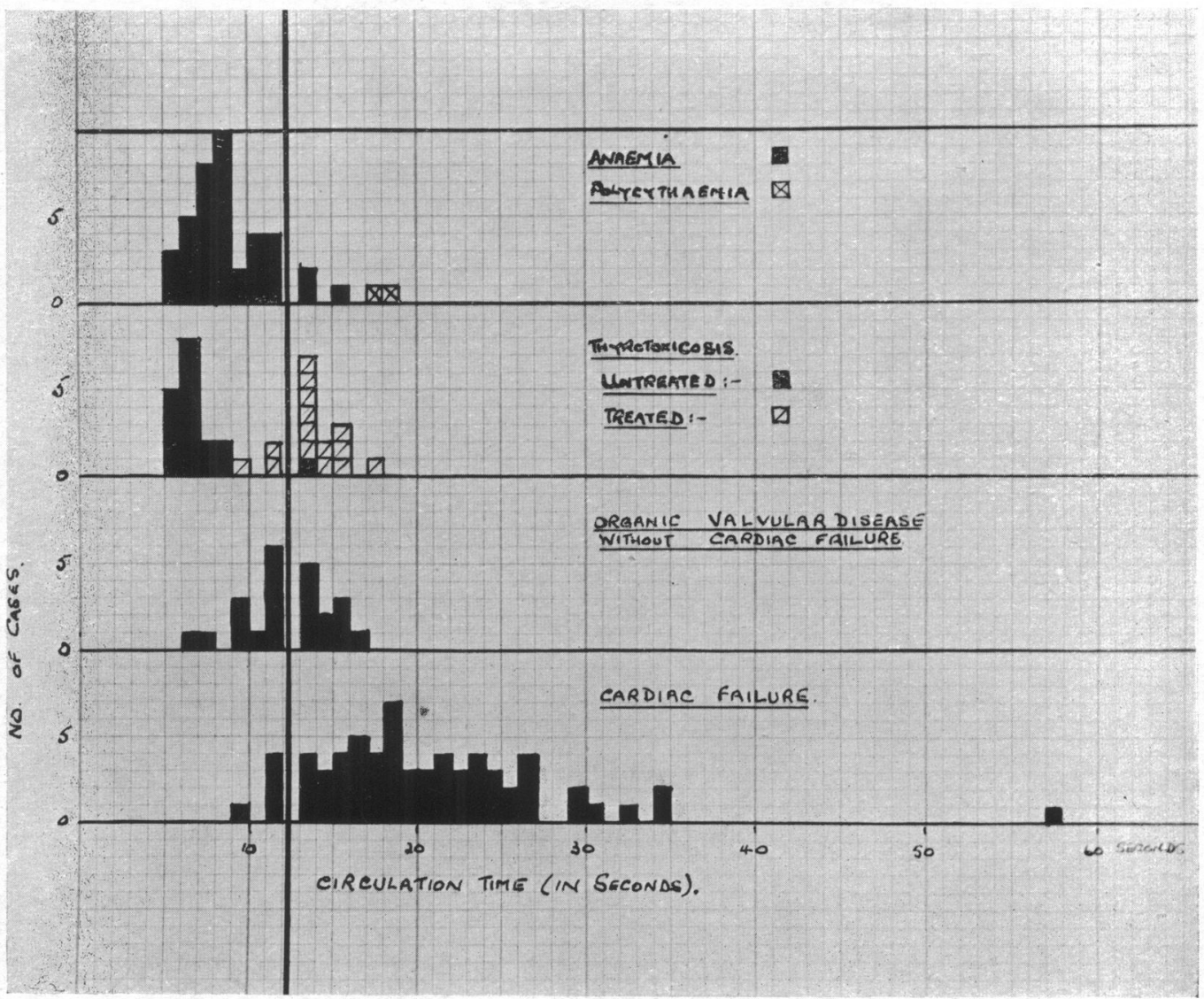

Fig. 1.-Diagram showing distribution of readings in the commoner conditions influencing circulation-time. Heavy vertical line at " normal mean" reading of $12 \cdot 1 \mathrm{sec}$.

TABLE III

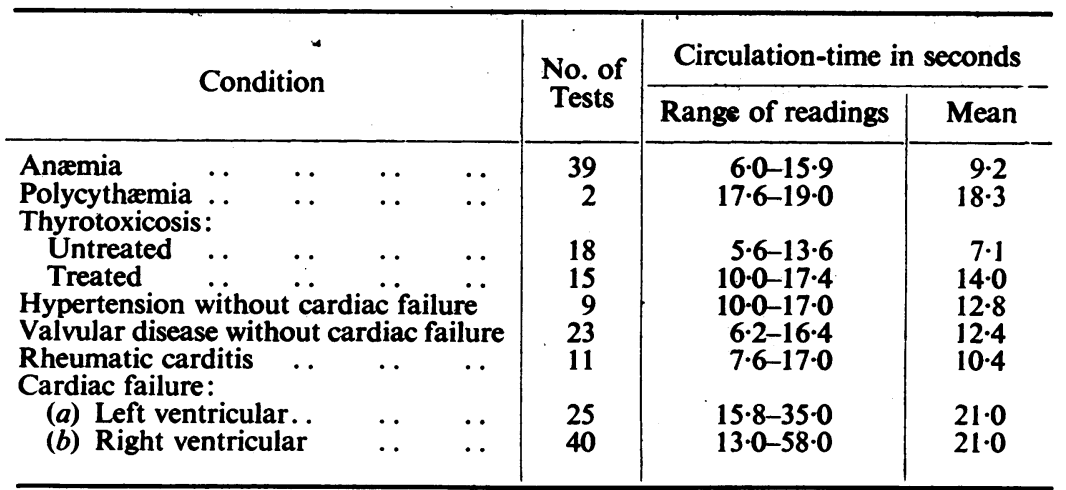


(3) Organic heart disease without clinical evidence of cardiac failure-22 cases, of which 14 had uncomplicated valvular lesions and 8 had been apparently cured of subacute bacterial endocarditis.

(4) Clinical cardiac failure- 48 cases, failure predominantly left ventricular in 19 , and right ventricular in 29.

The detailed results appear in Table III, and groups (3) and (4) are represented in Fig. 1. Successive tests in individual cases showed that deterioration or improvement in the clinical condition was accompanied by a corresponding rise or fall.

\section{SUMMARY AND CONCLUSIONS}

The commoner methods of blood circulation-time measurement have been reviewed, and the theophylline-ethylenediamine test was selected for clinical trial.

Extensive trials-involving 432 tests on 337 cases-are described and the results indicate that this method, which has the advantage of having an objective end-point, is safe, simple, and reliable, and eminently suitable for routine use.

In assessing the reliability of the test, the normal mean reading is almost identical with that of Fishberg's saccharin method-probably the most widely used of all-and duplicate readings correspond more closely than in the latter's series (Fishberg et al. 1933), being within physiological limits as shown by Stewart (1921). Satisfactory results were obtained from single and repeated tests in patients with anæmia, thyrotoxicosis, and cardiac failure.

This investigation was conducted during my tenure of a Research Assistantship in the University of Bristol, and I wish to record my thanks to the Physicians of Bristol Royal Infirmary for access to their cases, and to Professor C. Bruce Perry for his interest and encouragement.

\section{REFERENCES}

Allanby, K. D. (1949). Brit. Heart J., 11, 165.

Bain, C. W. C. (1934). Quart. J. Med., 3, 237.

Berliner, K. (1940). Arch. intern. Med., 65, 896.

Blumgart, H. L., and Yens, O. C. (1927). J. Clin. Invest., 4, 1.

Elek, S. R., and Solarz, S. D. (1942). Amer. Heart J., 24, 821.

Fishback, D. (1941). J. Lab. Clin. Med., 26, 1966.

Fishberg, A. M., Hitzig, W. M., and King, F. H. (1933). Proc. Soc. Exper. Biol. Med., 30, 651.

Koster, H., and Sarnoff, S. J. (1943). J. Lab. Clin. Med., 28, 812.

Loevenhart, A. S., Schlomovitz, B. H., and Seybold, E. G. (1922). J. Pharmacol. Exper. Therap., $19,221$.

Robb, G. P., and Weiss, S. (1933). Amer. Heart J., 8, 650.

Sperling, L., Weisman, S., and Papermaster, R. (1942), Surgery, 11, 600.

Stewart, G. N. (1921). Amer. J. Physiol., 58, 27.

Weiss, S., Robb, G. P., and Blumgart, H. L. (1929). Amer. Heart J., 4, 664.

Winternitz, M., Deutsch, J., and Brull, Z. (1931). Med. Klin., 27, 986. 